\title{
Use of DES for the Quantitative Analysis of the Workflow of the Hypertension Center at the "Azienda Ospedaliera Universitaria Federico II" of Naples
}

\author{
A. Torri, A. Pepino, M. Rovani, and N. De Luca
}

\begin{abstract}
The healthcare sector is very complex and healthcare managers have difficulty in describing the behavior of these systems. Management tools used by the managers of healthcare facilities, Business Intelligence for example, can help them to find the most suitable management solution in order to achieve the objectives that have been defined during the business planning phase, but they fail to fully describe the real workflow. This paper aims to develop a new operating paradigm that permits an improved definition of the operation of a healthcare structure by means of the adoption of simulated models based on Discrete Event Simulation (DES) theory in order to study its behavior and to obtain quantitative information about its activities and its use of human resources. The structure under scrutiny was the Hypertension Center of the "Azienda Ospedaliera Universitaria Federico II" of Naples.
\end{abstract}

Index Terms-Business process management, discrete event simulation, healthcare process analysis, simulation in healthcare.

\section{INTRODUCTION}

The Italian Healthcare Service operates in a condition of structural crisis in which healthcare managers have a limited amount of resources with which to meet the health needs of the population.

Healthcare managers need together a large amount of quantitative information about the execution of clinical processes in order to improve both the efficiency and efficacy of their units. Moreover, healthcare processes are very dynamic and so it is necessary to acquire real-time process data in order to obtain effective information concerning the workflow of the clinical processes

The purpose of this study is to demonstrate how it is possible to analyze the behavior of a complex system through the use of Discrete Event Simulation methodology (DES) as support to the classic management control systems in a unit such as the Hypertension Center of the "Azienda Ospedaliera Universitaria (AOU) Federico II of Naples", obtaining all the relevant information to its knowledge.

\section{The Simulation Method}

Simulation techniques are based on the development of suitable tools in which the representation of activities,

Manuscript received September 4, 2013; revised January 6, 2014.

A. Torri, A. Pepino, and M. Rovani are with the Department of Electrical Engineering and Information Technologies, University Federico II, Naples (e-mail: torri2005@libero.it).

N. De Luca is with the Department of Translational Medical Sciences, University Hospital Federico II, Naples. resources, time-dimension and relations between events is allowed [1]. The tools are programmed to execute the designed process in a time scale that is different from reality so that results can be obtained quicker than would normally be the case. Simulation allows systems to be studied and their behavior to be predicted in many contexts by simulating different operating conditions.

This aspect is particularly useful when it is required to deal with complex systems [2] like healthcare because it allows the testing of many different operative conditions. The benefits obtained by approaching the process analysis by means of simulation can be summarized as follows [3]:

- It permits the best choice to be made; by simulating different operative options, the manager can select the most appropriate to be applied to the system.

- It allows particular aspects of the systems to be focused upon; through the simulation it is possible to define each element of the system separately.

- It permits the search for alternatives; it is possible to quickly evaluate possible alternatives in the process workflow without destroying the current system;

- It allows problems to be identified; the simulation highlights critical aspects of the process such as bottlenecks, for example.

- It makes "What-if" analysis possible; many different conditions are set before the simulation so that the answer which would allow the system to deal with any kind of problem can be provided.

In spite of the above, the use of DES does raise some critical issues that need to be taken into account:

- The preliminary acquisition of historical data concerning the behavior of the system can be complex and timeconsuming.

- Providing all the functions required for a complex analysis is expensive. To design models that are able to represent reality, it is necessary to become aware of the system and this knowledge often requires a long time (several months) to acquire.

- The characteristics of a model can be complex and lead to the so-called 'spaghetti model' if not enough is known about it.

- Results are not always easy to interpret.

- Problems can arise if the complexity of the validation criterion of a model has not been clearly defined previously with the system's stakeholders and/or objective criteria in order to validate models are missing.

The present study was carried out by biomedical engineering students who were spending six months on a work experience placement in the unit. 
In this period, they had the opportunity to investigate the workflow in order to obtain the information which is outlined in the present study.

In this study, the technique of discrete event simulation was applied (DES) [4]-by means of the Simul8 simulation software [5] in order to investigate the potential of applying simulating techniques in Healthcare.

In Italy, the use of this type of tool is currently restricted to the military, manufacturing and logistical fields, although it has been widely experimented within the healthcare sector in the rest of Europe.

The particular system analyzed in this work is situated in a health care organization which was, therefore, obliged to operate responding to both strict national laws which require efficiency, effectiveness and economy, and to the health needs of the population. It is, therefore, important to define each element by means of particular features representing what happens in reality at a particular time. Particular probabilistic distributions can be used to represent the frequency of events. The DES technique allows the design of a particular reality and the simulation of its behavior through the definition of different elements as activities, and resources- that are extremely variable in the Healthcare Sector -and in terms of number, order and typology. The power of the DES technique is the chance it offers of modifying these parameters and of simulating different conditions in an easy and reproducible way.

\section{CAse Study: The A.O.U. Federico II - Hypertension CENTER}

The AOU Federico II of Naples is one of the main highly specialized public hospitals in south of Italy. Some of the main operative workflows are:

- Admission;

- Obstetrical/Gynecological first aid;

- Day Hospital;

- Day Surgery;

- Outpatient health services;

- Laboratory tests.

With the exception of admissions for obstetrical/gynecological pathologies which require emergency operations or urgent treatment, the management of medical/surgical activities in AOU Federico II is based on a waiting list system. These lists are managed in every department by doctors who are responsible for the out-patients.

The present work deals with the workflows of the Hypertension Centre which is one of the hospital's most important out-patient departments. It aims to simulate the process of patient care by analyzing costs, percentage of employment of resources, bottlenecks in the flow and the time between the patents booking an appointment and seeing a specialist doctor.

The final goal is to improve the performance of the process by guaranteeing a high quality service to every patient. This study is articulated in several phases:

\section{A. Phase 1: Model design}

The first part of the study was aimed at acquiring all the information necessary to design the workflow model that had to reflect reality as much as possible. With the agreement with the administrative directors of the centre, this information was collected through the direct observation of the activities managed within the Hypertension Centre and by interviewing the staff members.

After a preliminary observation, the basic structure of the department was drafted.

It consists of the following Units:

- 3 Examination Rooms for general examinations (hereby referred to as Lab A);

- 1 Non-invasive diagnostics Laboratory (hereby referred to as Lab B);

- 1 Laboratory of Diagnostics/Molecular Biology (hereby referred to as Lab C);

- 1 Laboratory of quality control and technology management (hereby referred to as Lab D).

These Units are also connected with some external structures: the Invasive Diagnostics Lab, the Day Hospital/Admission Unit and with the Intensive Coronary Treatment Unit (U.T.I.C.). The personnel organizational chart shows the following professional roles:

- 1 Director;

- 1 Associate Professor;

- 3 Researchers from the University;

- 4 Outpatient Expert;

- 1 Lab-medical Manager;

- 8 Specializing Doctors;

- 3 Health Managers (Biologists- Biotechnologists);

- 2 PhD Doctors;

- 1 Administrative Director.

The direct observation of the activities and the interviews with the staff members allowed the drawing up of a first schematic representation of the patient care-flow. The following steps were identified as the main tasks in the process:

- Preliminary patient examination; review of patient's medical history, check-up with pressure measurement, general medical examinations and ECG;

- Check-up: at this point, it is decided if any specific diagnostic exams examinations are required or if only the second check-up has to be scheduled;

- Day Service: it is usually scheduled during the first check up in order to deal with clinically complex situations, for which neither hospitalization nor the Day Hospital can deal with, although, of course, it is still necessary to provide the patient with suitable complete care;

- Day Hospital;

- Admission.

It was decided to focus on the workflow related to the management of preliminary examinations and checkup and diagnostic activities carried out within the Hypertension Centre.

Firstly, it was observed that there are 4 Laboratories which work on different days of the week. Secondly, different kinds of examinations were classified. In this way, the number of exams carried out every day in each laboratory was estimated, distinguishing between first examinations and follow up. Table I reports the number of examinations carried out in each of the four Labs (A, B, C, and D) on the different 
days of the week.

TABLE I: WEEKLY SCHEDULING OF EXAMINATION

\begin{tabular}{lll}
\hline \hline Day & Type of Examination & $\begin{array}{l}\text { Number of } \\
\text { Examinations }\end{array}$ \\
\hline MONDAY & & 30 \\
LaboratoryC & Check-up & 12 \\
Laboratory B & Check-up & 12 \\
Laboratory A & First Examination & 6 \\
TUESDAY & & 6 \\
Laboratory D & First Examination & 6 \\
WEDNESDAY & & 30 \\
Laboratory A & Check-up & 12 \\
Laboratory B & Check-up & 12 \\
Laboratory C & First Examination & 6 \\
THURSDAY & & 18 \\
Laboratory D & Check-up & 12 \\
Laboratory B & First Examination & 6 \\
FRIDAY & & 24 \\
Laboratory A & Check-up & 12 \\
Laboratory C & Check-up & 12 \\
\hline \hline
\end{tabular}

Secondly, the number and the type of resources available for each Laboratory, has been identified - Table II.

\begin{tabular}{ll} 
TABLE II: RESOURCES EMPLOYMENT WITHIN THE HYPERTENSION CENTRE \\
\hline \hline Laboratory & Resources \\
\hline Laboratory A & 1 Researcher + 1 Specializing Doctor \\
Laboratory B & 1 Researcher + 1 Specializing Doctor \\
Laboratory C & 1 Researcher + 1 Specializing Doctor \\
Laboratory D & 1 Researcher + 1 Specializing Doctor \\
Ultrasound & 1 Outpatient Expert + 2 Practicing Doctor + \\
Scanner Lab & 1Ultrasound Scanner Doctor \\
\hline \hline
\end{tabular}

Since the preliminary examination of the patient and the follow-up visit are characterized by the same sequence of activity, they have been displayed in Simul8 through the flow, shown in Fig. 1:

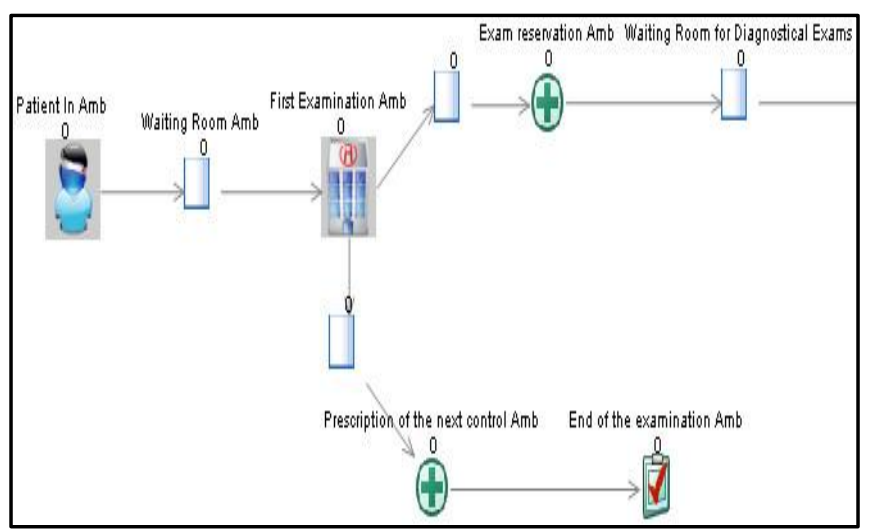

Fig. 1. Patients flow-care.

The most important part of the examined flow is the first examination of the patient. During this examination, the patient's personal details are taken, the informed consensus is signed by the patient and he or she is informed as regards anamnesis. After the first examination, the patient can either be discharged or undergo further examinations such as doppler ultra sound of the superior aortas of torso (Eco TSA) and multidimensional/two-dimensional heart examination by means of eco-color doppler.

These exams are booked by the doctor during the first visit and they are performed in the ultra sound scan lab. Only one ultrasound scan $l a b$ is currently set up in the centre so patients from all the different examination rooms are booked on a single waiting list whenever ultrasound examinations are required.

Since the laboratories of the Hypertension Center work alternately during the week, 5 different workflows need to be drawn up for each day. In order to analyze the worst case scenario, this study focuses on the activities performed on Wednesdays; the day on which all the labs of the center are open.

The workflow designed by using Simul8 is shown in Fig. 2 - in which there is a focus of the diagnostic activities.

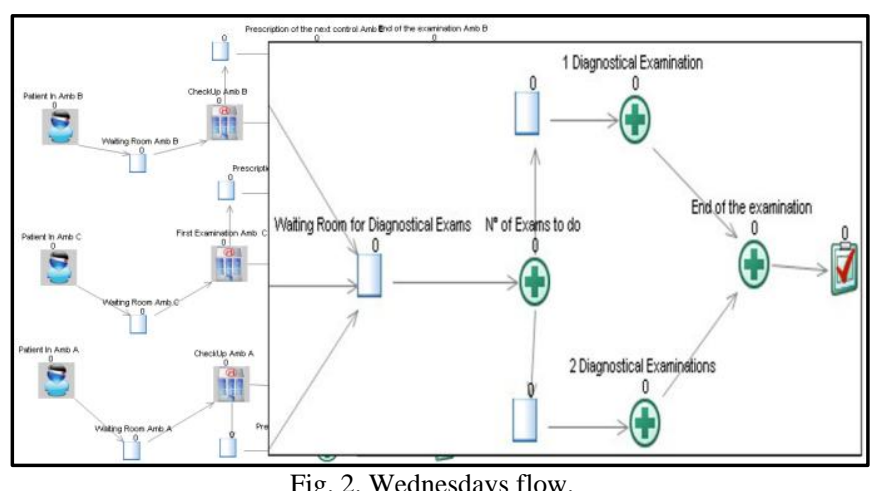

\section{B. Phase 2: Process Variables Definition}

Once the model of the workflow has been designed, all the parameters underlying the carrying out of the process have been defined. The definition of the parameters regulating the carrying out of the process is a necessary step in the change from design to realization. The variables of the process examined in this work are time and the resources involved in the carrying out of each activity, as highlighted in Table III:

TABLE III: PROCESS PARAMETERS

\begin{tabular}{lll}
\hline \hline Activity & Employed resource & $\begin{array}{l}\text { time } \\
{[\mathrm{min}]}\end{array}$ \\
\hline First examination & $\begin{array}{l}\text { 1 Researcher + 1 Specializing } \\
\text { Doctor } \\
\text { 1 Researcher + 1 Specializing } \\
\text { Doctor }\end{array}$ & 25 \\
Check-up & $\begin{array}{l}\text { 1 Outpatient Expert + } \\
\text { Specializing Doctor } \\
\text { Diagnostical }\end{array}$ & 15 \\
Examination & $\begin{array}{l}\text { 1 Outpatient Expert + 2 } \\
\text { Specializing Doctor } \\
\text { Examination }\end{array}$ & 30 \\
Exam reservation & $\begin{array}{l}\text { 1 Researcher + 1 Specializing } \\
\text { Doctor } \\
\text { 1 Researcher + 1 Specializing }\end{array}$ & 15 \\
$\begin{array}{l}\text { Prescription of the next } \\
\text { control }\end{array}$ & $\begin{array}{l}\text { Doctor } \\
1 \text { Researcher + 1 Specializing } \\
\text { Doctor }\end{array}$ & 3 \\
\hline \hline
\end{tabular}

\section{Phase 3: Costs Evaluation}

To carry out a global evaluation of the costs related to the carrying out of the process, many aspects need to be taken into account, as described below:

\section{1) Power and gas}

In order to estimate these costs, some assumptions have been made. The largest proportion of yearly expenditure is spent on heating in the winter and air conditioning in the 
summer. Based on the available data concerning these annual costs, the average cost per square meter was calculated by considering the total functional area of the Hypertension Centre. From the obtained value the cost per minute was calculated:

TABLE IV: RESOURCE COSTS

\begin{tabular}{ll}
\hline \hline Resource & Cost $(\epsilon$ per minute $)$ \\
\hline Power & 0,0017 \\
Heating /Energy thermo-refrigerating & 0,0017 \\
+ GAS & \\
& \\
\hline \hline
\end{tabular}

\section{2) Personnel}

For each employee category, the following costs were estimated. (Note that these cost do not include overtime, time slot, transport and other costs):

\begin{tabular}{lll}
\multicolumn{2}{c}{ TABLE V: PERSONNEL COSTS } \\
\hline \hline Profession & Period & Cost $C$ \\
\hline \multirow{3}{*}{ Researcher } & Year & $55.000,00$ \\
& Month & $4.583,33$ \\
& Minute & 0.50 \\
& Year & $42.000,00$ \\
Outpatient Expert & Month & $3.500,00$ \\
& Minute & 0,38 \\
& Year & $21.400,00$ \\
Specializing Doctor & Month & $1.783,33$ \\
& Minute & 0,20 \\
\hline \hline
\end{tabular}

\section{3) Ultrasound scanner}

The total amount (including the maintenance) declared in 5 years was considered and, from this value, the cost per minute was derived:

\section{TABLE VI: ULTRASOUNDS SCANNER'S COST}

\begin{tabular}{lll}
\hline \hline Ultrasounds Scanner Philips Mod.Sonos 5500 & $C$ \\
\hline Cost to be da amortized in 5 years & $X$ & 140000,0000 \\
Yearly Cost & $Y=X / 5$ & 28000,0000 \\
Daily Cost & $G=Y / 365$ & 76,7123 \\
Hour Cost & $H=G / 24$ & 3,1963 \\
Minute Cost & $I=H / 60$ & 0,0533 \\
\hline \hline
\end{tabular}

Once the cost of every resource has been defined, it is possible to estimate a cost for every activity.

\section{Phase 4: Routing Parameters Definition}

Within the workflow and while the simulation is running, each patient is represented by a token and each token is given a label. This allows the route of each token within the workflow to be defined and establishes which activity the token must be directed towards.

The type of visit (first visits etc.) and the first appointment is usually defined on the basis of the information provided by data stored in the Information System Center.

More particularly, starting from the first examination, we supposed that patients come to the Hypertension Centre after registration, and that, afterwards, they are sorted firstly as regards which examination room they should go to and then from these rooms to which labs they go to, depending to the doctors' prescriptions. The mechanism that determines the patient's routing to a particular examination room is stochastic and it depends only on which day the patient comes to the centre for examination.

Since the first examination takes twice the time required for the check-up, it is supposed that for every 12 planned check-ups, six examinations are carried out.

Once the first examination is completed, patients may be required to undergo a single instrumental examination or a double one. A double exam is usually recommended to those patients who come to the center for the first time in order to better define their clinical situation. As regards check-up visits, a single exam is usually required.

Sometimes, patients come to the center after they have already undergone diagnostic examinations so it is not necessary to repeat them.

The present study examines a population of 500 patients admitted to the clinic from June 2012 to December 2012, both for first examinations and for check-up.

These patients were classified - on the basis of their individual medical history - according to the classification of the "ProgettoCuore" [7] (7 groups of low/medium/high cardiovascular risk) in the following way:

- Gender;

- Diabetes;

- Age, expressed in years and considered in decades, 40-49, 50-59, 60-69;

- Smoker or non-smoker;

- Range of arterial blood systolic pressure;

- Cholesterol expressed in $\mathrm{mg} / \mathrm{dl}$.

On the basis of the above criteria, the patients were statistically classified into different "Cardiovascular Risks" classes:

- $<5 \%$;

- From $5 \%$ to $10 \%$;

- From $10 \%$ to $20 \%$;

- From $20 \%$ to $40 \%$;

- $>40 \%$.

A specific label indicating the risk class was assigned to each patient.

The percentage of patients belonging to each class was calculated. The probability density function (Pdf) that, working from a statistical base, is able to assign a specific label representative of the particular risk class to every input token was then defined. Within every class, the threshold which allows the decision as to whether the patient needs particular instrumental examinations to be carried out was defined on the basis of the string of values defined for the parameters described above (cholesterol, age, blood pressure). These thresholds were inserted in a spreadsheet and the functions permitting the comparison of the values of the parameters to the defined thresholds were implemented in Visual Logic in order that the tokens could be routed within the workflow.

Two functions were implemented for the routing

- The first one was able to define whether the patient needs further examinations after the first visit or if he could be discharged;

- The second allows number of exams necessary for each patient to be established. 
The number of tokens within the flow depends, therefore, on the number of available laboratories on the particular day of the week and on the risk class to which the patient belongs since that influences the number of examinations required.

The following Table indicates the number of tokens introduced into the workflow for each day of the week. This number was calculated on a statistical basis considering the characteristics of the examined population.

\begin{tabular}{ll}
\multicolumn{2}{c}{ TABLE VII: NUMBER OF TOKEN (PATIENTS) EACH DAY } \\
\hline \hline Day & Number of Token \\
\hline Monday & 30 \\
Tuesday & 6 \\
Wednesday & 30 \\
Thursday & 18 \\
Friday & 24 \\
\hline \hline
\end{tabular}

Two functions determine the patient's routing within the workflow:

- One, which is related to the first examination, allows for an incoming patient every 10 minutes until a maximum of 6 patients for each examination room is reached.

- One, which is related to the check-up, that allows for an incoming patient every 5 minutes until a maximum of 12 in each examination room is reached.

The FIFO (First in First Out) mode was set to handle the queues within the flow. The observation time corresponds to the time required for the simulation.

\section{E. Phase 5: Simulation Execution}

Once the parameters described above are defined, the simulation is used to estimate the following KPI:

- Number of complete instances.

- Waiting time for the execution of each activity.

- Resource utilization percentage for each activity.

- Global percentage of resources utilization.

- Minimum/Average/ Maximum Time staying in the system.

TABLE VIII: WEDNESDAY WORKFLOW SIMULATION: RESULTS

\begin{tabular}{|c|c|c|c|}
\hline Time & & Resource & Use \\
\hline \multirow{3}{*}{$\begin{array}{l}\text { Time staying } \\
\text { in the flow }\end{array}$} & Min $\quad 51,14$ & Doctor A & $50,79 \%$ \\
\hline & Avg $\quad 182,87$ & Doctor B & $47,53 \%$ \\
\hline & $\operatorname{Max} \quad 309,72$ & Doctor C & $36,37 \%$ \\
\hline $\begin{array}{l}\text { Type of } \\
\text { examinations }\end{array}$ & $\begin{array}{l}\text { N. of } \\
\text { examinations } \\
\text { performed }\end{array}$ & $\mathrm{ECO}$ & $93,62 \%$ \\
\hline Paz. 1 exam & 5 & $\begin{array}{l}\text { Specializing Doctor } \\
\text { A }\end{array}$ & $50,79 \%$ \\
\hline Paz. 2 exam & 8 & $\begin{array}{l}\text { Specializing Doctor } \\
\text { B }\end{array}$ & $47,53 \%$ \\
\hline Paz. 0 exam & 15 & $\begin{array}{l}\text { Specializing Doctor } \\
\text { C }\end{array}$ & $36,37 \%$ \\
\hline Uncompleted & 2 & $\begin{array}{l}\text { Specializing Doctor } \\
\text { ECO1 }\end{array}$ & $93,62 \%$ \\
\hline \multirow[t]{2}{*}{ Total } & \multirow[t]{2}{*}{30} & $\begin{array}{l}\text { Specializing Doctor } \\
\text { ECO2 }\end{array}$ & $46,81 \%$ \\
\hline & & Ultrasound Scanner & $88,48 \%$ \\
\hline
\end{tabular}

Table VIII summarizes the data obtained by simulating the carrying out of the process and basing it on the workflow drawn up by considering the activities carried out on Wednesdays (as represented above in Fig. 2).

Starting from the results above, it is possible to gather information about the costs incurred by the center during the period under scrutiny:

\begin{tabular}{ll}
\multicolumn{2}{c}{ TABLE IX: COSTS ANALYSIS } \\
\hline \hline Total cost & $\epsilon$ \\
\hline Wednesday working activity & 689,09 \\
\hline \hline
\end{tabular}

\section{F. Phase 6: Results Evaluation}

The results obtained by means of the simulation and highlighted in Table VIII, were compared with the results deriving from the carrying out of the actual process, described in Table I, in order to verify the accuracy of the model designed "by hand" and the effectiveness of the simulation technique. This type of verification is called black box verification.

The compliance of the designed model with reality is an essential requirement if the actual process is to be simulated. It is possible to assume that every change applied to the simulating parameters in the simulation software would have an analogous effect in the real world only if the results derived from the simulation reflect the changes occurring in the actual process.

The same assumptions hold for the queue in the laboratory. The model and the results obtained by applying the simulation techniques were shown to the experts in this field, the physicians that work in the center, for example and they confirmed that the simulated model complied with the actual process.

Once the simulation model have been verified, it is then possible to state that the waiting time measured during the simulation is the same as that in reality. The total number of patients in input to the workflow coincides with the effective number of patients treated on Wednesday. The same holds for the average staying time of patients in the flow.

The workflow concerning the instrumental lab shows that the number of exams required exceeds the capacity of the resources available. Furthermore, the average maximum staying times of patients in the workflow are particularly high - Table VIII.

In light of this, some solutions were identified in order to improve performance.

\begin{tabular}{|c|c|c|c|c|c|}
\hline \multicolumn{2}{|l|}{ Solution 1} & \multirow{2}{*}{$\frac{\text { Wednesday }}{28,01}$} & \multicolumn{2}{|c|}{ “AS-IS" Model } & \multirow{2}{*}{$\frac{\text { Wednesday }}{51,14}$} \\
\hline \multirow{3}{*}{$\begin{array}{l}\text { Time of } \\
\text { staying in the } \\
\text { flow [min] }\end{array}$} & Min & & \multirow{3}{*}{$\begin{array}{l}\text { Time } \\
\text { of } \\
\text { staying } \\
\text { in the } \\
\text { flow } \\
\text { [min] }\end{array}$} & Min & \\
\hline & Avg & 155,09 & & Avg & 182,87 \\
\hline & Max & 256,42 & & Max & 309,72 \\
\hline \multicolumn{2}{|l|}{ Cost $[\epsilon]$} & 665,51 & \multicolumn{2}{|l|}{ Cost $[\epsilon]$} & 689,09 \\
\hline \multicolumn{2}{|c|}{ Total Patients Number } & 30 & \multicolumn{2}{|c|}{$\begin{array}{l}\text { Total Patients } \\
\text { Number }\end{array}$} & 30 \\
\hline \multicolumn{2}{|c|}{$\begin{array}{l}\text { Patients Number in } \\
\text { process }\end{array}$} & 0 & \multicolumn{2}{|c|}{$\begin{array}{l}\text { Patients Number } \\
\text { in process }\end{array}$} & 2 \\
\hline
\end{tabular}


Firstly, it was supposed that all patients undergoing diagnostic examination had already informed their doctors about their health status, and so the risk class to which they belong was already known. Consequently, it is possible to manage their routing in the workflow on the basis of this information. Patients undergoing the first medical examination join the workflow according to the order of the requests. In this way, as shown in the Table X, both a waiting time reduction and an optimization of employed resources can be obtained.

Since patients do not always respect the time scheduled for their visits and there are frequently mistakes and delays, a further option was analyzed:

- the addition of a second instrumental lab requiring the employment of additional resources:

a) Expert Doctor;

b) Specializing Doctors;

- and instruments:

a) new Ultrasound Scanner.

Adding a new examination room the laboratory to compensate for the costs of the rooms equipment was proposed.

TABLE XI: RE-ENGINEERING FLOW - SOLUTION 2

\begin{tabular}{|c|c|c|c|c|c|}
\hline \multicolumn{3}{|l|}{ Solution 2} & \multicolumn{3}{|c|}{ "AS-IS" Model } \\
\hline Day & $\begin{array}{l}\text { Type of } \\
\text { exam. }\end{array}$ & $\begin{array}{l}\text { N. of } \\
\text { Exam. }\end{array}$ & Day & $\begin{array}{l}\text { Type of } \\
\text { exam. }\end{array}$ & $\begin{array}{l}\text { N. of } \\
\text { Exam. }\end{array}$ \\
\hline MON. & $\begin{array}{l}\text { Total } \\
\text { exam. }\end{array}$ & 30 & MON. & $\begin{array}{l}\text { Total } \\
\text { exam. }\end{array}$ & 30 \\
\hline Lab. C & Check-up & 12 & Amb.C & Check-up & 12 \\
\hline Lab. B & Check-up & 12 & Amb. B & Check-up & 12 \\
\hline Lab. A & First exam. & 6 & Amb. A & $\begin{array}{l}\text { First } \\
\text { exam. }\end{array}$ & 6 \\
\hline TUE. & $\begin{array}{l}\text { Total } \\
\text { exam. }\end{array}$ & 18 & TUE. & $\begin{array}{l}\text { Total } \\
\text { exam. }\end{array}$ & 6 \\
\hline Amb. D & First exam. & 6 & Amb. D & $\begin{array}{l}\text { First } \\
\text { exam. }\end{array}$ & 6 \\
\hline Amb. E & Check-up & 12 & & & \\
\hline WED. & $\begin{array}{l}\text { Total } \\
\text { exam. }\end{array}$ & 30 & WED. & $\begin{array}{l}\text { Total } \\
\text { exam. }\end{array}$ & 30 \\
\hline Lab. A & Check-up & 12 & Lab.A & Check-up & 12 \\
\hline Lab. B & Check-up & 12 & Lab. B & Check-up & 12 \\
\hline Lab.C & First exam. & 6 & Lab. C & $\begin{array}{l}\text { First } \\
\text { exam. }\end{array}$ & 6 \\
\hline THUR. & $\begin{array}{l}\text { Total } \\
\text { exam. }\end{array}$ & 30 & THUR. & $\begin{array}{l}\text { Total } \\
\text { exam. }\end{array}$ & 18 \\
\hline Lab. B & First exam. & 6 & Lab. B & $\begin{array}{l}\text { First } \\
\text { exam. }\end{array}$ & 12 \\
\hline Lab. D & Check-up & 12 & Lab. D & Check-up & 6 \\
\hline Lab. E & Check-up & 12 & & & \\
\hline FRI. & $\begin{array}{l}\text { Total } \\
\text { exam. }\end{array}$ & 30 & FRI. & $\begin{array}{l}\text { Total } \\
\text { exam. }\end{array}$ & 24 \\
\hline Lab. A & Check-up & 12 & Lab. A & Check-up & 12 \\
\hline Lab.C & Check-up & 12 & Lab. C & Check-up & 12 \\
\hline Lab. E & First exam. & 6 & & & \\
\hline
\end{tabular}

Maintain active 3 examination rooms during the operative days of the week were also proposed. In Table XI, the results obtained by applying such modifications are presented.
By simulating the workflow for seven days, the following results were obtained:

TABLE XII: RE-ENGINEERING FLOW- SOLUTION 2: RESULTS

\begin{tabular}{|c|c|c|c|c|c|}
\hline \multicolumn{2}{|l|}{ Solution 2} & \multirow{3}{*}{$\begin{array}{l}\text { Wednesday } \\
50,75 \\
70,99\end{array}$} & \multicolumn{2}{|c|}{ “AS-IS" Model } & \multirow{2}{*}{$\begin{array}{l}\text { Wednesday } \\
51,14\end{array}$} \\
\hline \multirow{6}{*}{$\begin{array}{l}\text { Time of staying } \\
\text { in the flow } \\
\text { [min] }\end{array}$} & \multirow{2}{*}{ Min } & & \multirow{6}{*}{$\begin{array}{l}\text { Time of } \\
\text { staying in } \\
\text { the flow } \\
\text { [min] }\end{array}$} & Min & \\
\hline & & & & 1VIIII & \\
\hline & Ayo & 138,39 & & Avo & 182,87 \\
\hline & & 130,18 & & Avg & \\
\hline & \multirow{2}{*}{ Max } & 220,52 & & Max & 30972 \\
\hline & & 192,10 & & & \\
\hline \multicolumn{2}{|l|}{ Cost $[\epsilon]$} & 718,17 & \multicolumn{2}{|l|}{ Cost $[\epsilon]$} & 689,09 \\
\hline \multicolumn{2}{|c|}{ Total Patients Number } & 30 & \multicolumn{2}{|c|}{$\begin{array}{l}\text { Total Patients } \\
\text { Number }\end{array}$} & 30 \\
\hline \multicolumn{2}{|c|}{$\begin{array}{l}\text { Patients Number who } \\
\text { don't end the } \\
\text { procedures }\end{array}$} & 0 & \multicolumn{2}{|c|}{$\begin{array}{l}\text { Patients Number } \\
\text { who don't end the } \\
\text { procedures }\end{array}$} & 2 \\
\hline
\end{tabular}

Moreover, referring to a period of one week, we evaluated:

- the total costs sustained from the structure.

- the number of patients treated.

- the number of patients whose requests are pending at the end of the simulation period in both the actual and the hypothetic conditions.

TABLE XIII: COMPARISON BETWEEN TOTAL COSTS AND NUMBER OF FULFILLED AND PENDING REQUESTS

\begin{tabular}{llll}
\hline \hline $\begin{array}{l}\text { Considered } \\
\text { Case }\end{array}$ & $\begin{array}{l}\text { N. of Treated } \\
\text { Patients }\end{array}$ & $\begin{array}{l}\text { N. of Pending } \\
\text { Requests }\end{array}$ & $\begin{array}{l}\text { Total } \\
\text { Costs }\end{array}$ \\
\hline Actual case & 108 & 4 & 2584,72 \\
Solution 1 & 108 & 0 & 2414,78 \\
Solution 2 & 138 & 0 & 3327,78 \\
\hline \hline
\end{tabular}

Finally, we calculated, and compared in Table XIV, the costs of the services provided obtained for each case considered:

\begin{tabular}{ll}
\multicolumn{2}{c}{ TABLE XIV: COSTS COMPARISON } \\
\hline \hline Case & Global Cost $[\epsilon]$ \\
\hline Real case & 30,055 \\
Solution 1 & 25,154 \\
Solution 2 & 28,937 \\
\hline \hline
\end{tabular}

\section{CONCLUSION}

The results above show that solution 1 permits a decreasing in the waiting time with the same costs and same resources and personnel as in reality. By applying solution 2, a reduction in costs can be obtained as well as a decrease in the waiting time, even if a significant expenditure is required to equip the Laboratory. Indeed, the number of exams that can be performed is significantly higher.

This study showed how simulation techniques allow a quantitative analysis of the carrying out of the actual process in order to identify the process parameters which can be changed in order to then test different working conditions, and to highlight suitable hypothesis for the re-engineering of the process itself so that better results may be achieved. In this way, the effects on the real situation of all the modifications applied can be quantitatively measured before they are applied. In [8] Connelly et al. reached similar 
conclusions as regards the powerful potential of DES for representing complex environments like healthcare. They used DES to compare two triages methods and showed how is it possible by means of this technique to gather quantitative information to evaluate different options. They performed a quantitative measure of the accuracy of their model as compared to reality, and although this measure can be helpful in order to evaluate possible mistakes, in this work we preferred to consider the opinion of the personnel directly involved in the process in the design of the model.

\section{REFERENCES}

[1] J. Banks, J. S. Carson II, B. L. Nelson, and D. Nicol, Discrete-Event System Simulation, 3rd ed. Englewood Cliffs, NJ: Prentice-Hall, 2000.

[2] G. B. Ronsivalle, Simulare la complessità: Sistemi dinamici e reti decisionali nei percorsi di apprendimento, 2005.

[3] M. Law and W. D. Kelton, "Simulation modeling and analysis," McGraw-Hill, 2000.

[4] S. Brailsford and N. Hilton, "A Comparison of Discrete Event Simulation and System Dynamics," School of Management University of Southampton, UK, 2011.

[5] SIMUL8. [Online]. Available: http://www.simul8.com/evalu8.htm

[6] W. M. P. van der Aalst, "Discovery," Conformance and Enhancement of Business Processes, Springer-Verlag, Berlin Heidelberg, 2011.

[7] S. Giampaoli, "Vanuzzo D. Il Progetto CUORE - Studi Longitudinali," in Atlante italiano delle malattie cardiovascolari, 2 nd ed. ItalianHeart J., 5(Suppl 3):94S-101S, 2004.

[8] L. G. Connelly and A. E. Bair, "Discrete event simulation of emergency department activity: A platform for system-level operations," Academic Emergency Medicine, vol. 11, no. 11, pp. $1177-1185,2004$.

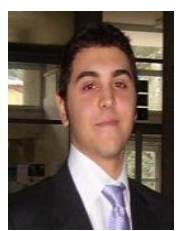

Torri Adriano was born in Naples on February 1, 1984. He got his degree in biomedical engineering at the University of Naples "Federico II", Italy, 2011. He worked as a PhD student at the University of Naples "Federico II" since 2012.

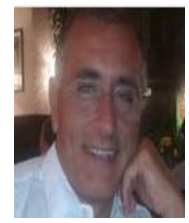

Pepino Alessandro was born in Naples on June 19, 1958. $\mathrm{He}$ graduated with praise in electronic engineering (biomedical address) at the University of Naples "Federico II", Italy, 1982. He got his $\mathrm{PhD}$ in Bioengineering in 1987. He was an associate professor at University of Naples "Federico II" since 1998. His main Simulation in Health.

interests are E-Health, Rehabilitation Engineering, DES

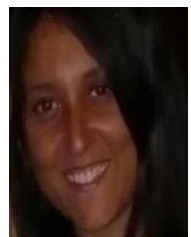

Rovani Marcella was born in Naples, in November 12 1984. She got her degree in biomedical engineering at the University of Naples "Federico II", Italy, 2009. She since 2011 worked as PhD student at the University of Naples "Federico II" and she is currently working in the Quality Sector of a Pharmaceutical Company.



De Luca Nicola was born in Naples on December 18, 1955. He graduated in Medicine in 1979, Clinical Postgraduate Residency in Cardiology and in Pneumology. He got award of the Italian Society of Hypertension in 1989 and of the Italian Society of Cardiology in 1990. Since 2001 he was an associate professor at University of Naples "Federico II", since 2012 he was the chief of the Hypertension Center of the University of Naples "Federico II", since 2008 he was the director of Clinical Physiopathology Division at "Federico II" University Hospital. M. D. De Luca is a co-author of about 250 Publications with main interest in arterial hypertension, in the role of sympathetic system in cardiovascular diseases and in the regulation and in the progression of cardio-vascular structural changes. Secondary interest is in health applications of innovation technologies for the follow-up of chronic pathologies. 